\title{
(C) OPEN ACCESS \\ Communication quality between the medical team and the head coach/manager is associated with injury burden and player availability in elite football clubs
}

\author{
Jan Ekstrand, ${ }^{1,2}$ Daniel Lundqvist, ${ }^{3}$ Michael Davison, ${ }^{2,4}$ Michel D'Hooghe, ${ }^{2,5}$ \\ Anne Marte Pensgaard ${ }^{6}$
}

${ }^{1}$ Division of Community Medicine, Department of Medical and Health Sciences, Linköping University, Linköping, Sweden

${ }^{2}$ Football Research Group, Linköping, Sweden ${ }^{3}$ Unit of Education and Sociology, Department of Behavioural Sciences and Learning, Linköping University, Linköping, Sweden

${ }^{4}$ Isokinetic Medical Group, FIFA Medical Centre of Excellence, London, UK

${ }^{5}$ Union of European Football Associations (UEFA), Nyon,

Switzerland

${ }^{6}$ Department of Coaching and Psychology, Norwegian School of Sport Sciences, Oslo, Norway

\section{Correspondence to}

Professor Jan Ekstrand, Division of Community Medicine,

Department of Medical and Health Sciences, Linköping University, Linköping 582 21, Sweden;

jan.ekstrand@telia.com

Accepted 23 July 2018 Published Online First 13 August 2018
Check for updates

(c) Author(s) (or their employer(s)) 2019. Re-use permitted under CC BY-NC. No commercial re-use. See rights and permissions. Published by BMJ.

To cite: Ekstrand J Lundqvist D, Davison M, et al. Br I Sports Med 2019:53:304-308.

\section{ABSTRACT}

Objectives We investigated medical staff interpretations and descriptions of internal communication quality in elite football teams to determine whether internal communication was correlated with injuries and/or player availability at training and matches.

Methods Medical staff from 36 elite football clubs across 17 European countries produced 77 reports at four postseason meetings to provide their perceptions of internal communications in their teams. They also recorded data on individual players' exposure to football and time-loss injuries.

Results The injury burden and incidence of severe injuries were significantly higher in teams with low quality of communication between the head coach/ manager and the medical team (scores of 1-2 on a 5-point Likert scale) compared with teams with moderate or high-quality scores (scores of 3-5; $p=0.008$ for both). Teams with low scores had 4\%-5\% lower training attendance $(76 \%$ vs $83 \%, p=0.001)$ and less availability at matches ( $82 \%$ vs $88 \%, p=0.004$ ) compared with teams with moderate or high communication quality scores.

Conclusions The quality of internal communication within a team was correlated with injury rates, training attendance and match availability.

\section{INTRODUCTION}

During the 2000s, in elite men's football teams, the rates of overall, match and training attendance and muscle injury have been stable. ${ }^{12}$ Preventive strategies that targeted player-related risk factors have not led to significant reductions in injury rates at the elite level. ${ }^{3}$

When asked for their views on the most important risk factors contributing to injuries and injury burden, ${ }^{4}$ chief medical officers of clubs in the UEFA Elite Club Injury Study ${ }^{1}$ responded with four most common factors: (i) the workload imposed on players, (ii) player well-being, (iii) the quality of internal communication within the team and (iv) the head coach's leadership style. ${ }^{56}$ Verbal and non-verbal communications were considered important mediators of performance in team sports, but few sports-related studies have directly measured such communication.

We investigated the quality of internal communication in elite football teams and evaluated whether internal communication was correlated with injuries and player availability at training and matches. We also tested how the injury rate and player availability were influenced by the internal communication within the medical team as well as the communication between the medical team and different organisational club positions, that is, head coach, fitness coach, chief executive officer (CEO) and president/board.

\section{MATERIALS AND METHODS}

This study was conducted as a substudy of the ongoing UEFA Elite Club Injury Study (ECIS), where 36 elite-level football teams from 17 European countries were followed from 2012 to 2016 At the annual postseason meetings of the ECIS, team chief medical officers were asked to assess internal communication within their clubs. A total of 77 reports were generated during the meetings. Data on injuries and exposure to football were collected for all 36 teams during the four seasons.

\section{Data collection}

Independent variable: quality of internal

communication within the club

A member of the medical staff on each team completed a questionnaire to describe their perception of the quality of communication within the club. Communication quality was rated on a 5 -point Likert scale ranging from 'not good at all' $($ score $=1)$ to 'very, very good' (score $=5)$. High numbers denoted better quality internal communication. We evaluated the quality of different subtypes of internal communication, including between different individuals on the medical team (team doctors vs physiotherapists) and between individuals on the medical team and individuals in other positions within the team (ie, medical team and head coach/manager, medical team and fitness coaches, medical team and CEO, medical team vs. president/board). Then, the overall level of quality of internal communication was calculated as the average of all these scores.

Outcome measures/dependent variables: injury data Data on injuries were collected in accordance with the consensus statement on injury definitions and data collection procedures in studies on football (soccer) injuries, ${ }^{8}$ and the general methodology was identical to that employed by Hägglund et al. ${ }^{99}$

An injury was defined as any physical complaint that occurred while participating in a football match or a training session that led to an inability to participate fully in a future training session or 
match (ie, a time-loss injury). Players remained in an injured status until the club's medical staff allowed full participation in training and released the player for selection in matches. A severe injury was defined as an injury that resulted in an absence of $>28$ days from training or matches.

Baseline data on players were collected when players were first included in the study. Additionally, on inclusion, all players consented to participate in the study. A member of the club's medical staff recorded data on individual players, including their exposure to football (in minutes) during all training sessions and matches. Injury and attendance reports were sent to the study group once per month. Reports were checked by the study group on receipt, with prompt feedback sent to the clubs for corrections on any missing or unclear data. Each injury was coded in accordance with a modified version of the Orchard Sports Injury Classification System V.2.0.9. ${ }^{10}$

The risk of injury over a season was evaluated for the players of each team, based on four criteria that were previously found to be correlated with team performance, ${ }^{11}$ as follows:

i. Injury burden: (total number of days of absence/total number of hours of exposure) $\times 1000$. This variable accounted for both the incidence and severity of injuries in a season.

ii. Incidence of severe injuries: (total number of injuries causing absences of $>28$ days/total number of hours of exposure) $\times 1000$

iii. Attendance at training: average training attendance in a season, expressed as a percentage

iv. Availability for matches: average availability for matches in a season, expressed as a percentage.

\section{Statistical analyses}

We used Spearman's rho correlation coefficient to assess the relationship between the internal communication scores and the four outcome measures (ie, injury burden, incidence of severe injuries, attendance at training and availability for matches). The scores from the five individual subtypes of internal communication were averaged to produce an overall score. Then, depending on the overall internal communication score, teams were assigned to one of three levels of communication, as follows: low quality (overall scores $=1-2$ ), moderate quality (overall score $=3$ ) or high quality (overall scores $=4-5$ ). Differences in the four outcome measures among the low, moderate and high groups were analysed with Kruskal-Wallis (KW) tests. When the KW results were statistically significant, we compared outcomes between each pair of groups (low vs moderate, low vs high and moderate vs high) with Mann-Whitney tests.

In addition, effect sizes ( $r$ ) were calculated with results from the Mann-Whitney tests. We classified 0.1 as a small effect, 0.3 as a medium-sized effect and 0.5 as a large effect, as suggested by Cohen. ${ }^{12}$ All analyses were two-sided, and the significance level was set at $\mathrm{p}<0.05$. The Bonferroni correction was applied for comparisons between individual groups, with a significance level of $p<0.0167$. We performed all analyses with IBM SPSS Statistics for Windows V.23.0.

\section{RESULTS}

Medical staff assessments of the quality of internal communication are shown in figure 1 . The best communication was within the medical team (ie, between doctors and physiotherapists), with a mean score of 4.5 (range 2-5) on the 5-point Likert scale. Communication between other team members varied, with mean scores between 3.4 and 3.9 (range 1-5 for all).

\section{Overall internal communication and injury rates}

The highest overall quality of communication (5 out of 5) was correlated to a low injury burden ( $\mathrm{rs}=-.31, \mathrm{p}=0.007$ ); a low incidence of severe injuries ( $\mathrm{rs}=.-32, \mathrm{p}=0.005)$; a high training attendance $(\mathrm{rs}=0.31, \mathrm{p}=0.006)$ and high match availability (rs $=0.27, \mathrm{p}=0.048)$.

\section{Communication between the head coach/manager and the medical team}

Both the injury rates and player availability were significantly different across the high, moderate and low groups of internal communication between the head coach or manager and the medical staff of the team (table 1).

Teams with low communication quality (ie, who scored $1 / 5$, these comprised $10 \%$ of teams) had significantly higher injury burden and higher incidence of severe injury compared with teams with moderate $(\mathrm{p}=0.009$ and 0.017 , respectively) or high $(\mathrm{p}=0.014$ and 0.010 , respectively) communication quality. Teams with low communication quality also had lower attendance at training and lower availability at matches compared

\section{$1=$ Not good at all}

\section{$5=$ very, very good}

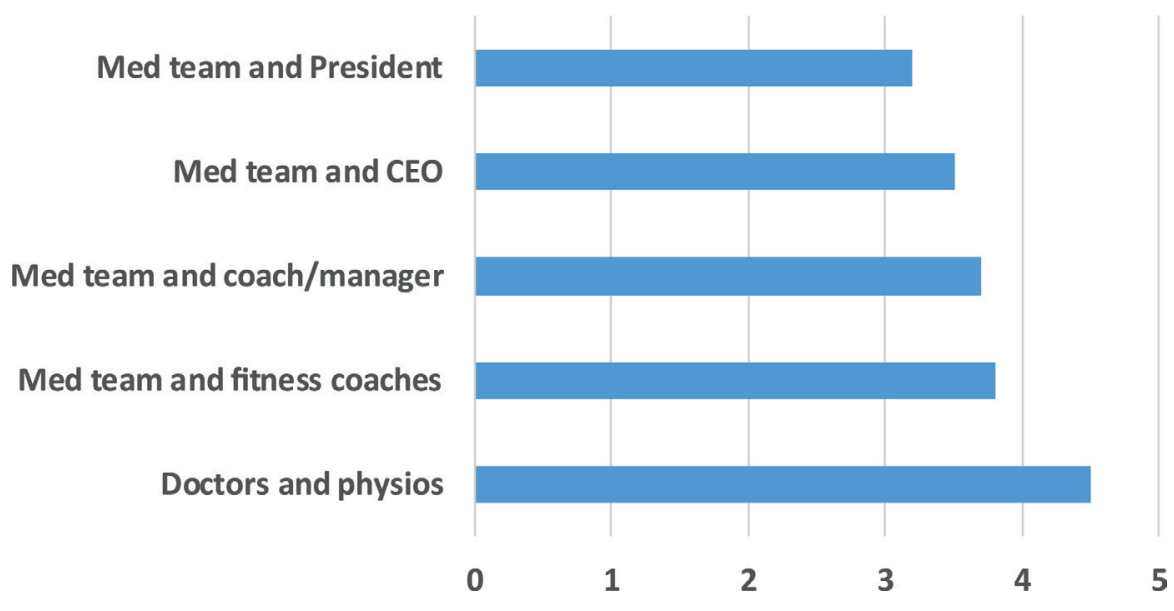

Figure 1 Medical staff assessments of communications between stakeholders within each football club. Values represent ratings on a 5-point Likert scale ranging from 'not good at all' (1) to 'very, very good' (5). CEO, chief executive officer; Med, medical; physios, physiotherapists. 


\begin{tabular}{|c|c|c|c|c|}
\hline Outcomes* & $\begin{array}{l}\text { Low }(1-2 / 5), \\
n=8\end{array}$ & $\begin{array}{l}\text { Moderate } \\
(3 / 5), n=18\end{array}$ & $\begin{array}{l}\text { High }(4-5 / 5) \text {, } \\
n=51\end{array}$ & $P$ valuest \\
\hline Injury burden $\ddagger$ & 183.6 & 120.7 & 105.0 & 0.027 \\
\hline $\begin{array}{l}\text { Incidence of } \\
\text { severe injuries§ }\end{array}$ & 1.7 & 1.0 & 0.9 & 0.025 \\
\hline $\begin{array}{l}\text { Training } \\
\text { attendance (\%) }\end{array}$ & 76.2 & 85.3 & 83.4 & 0.003 \\
\hline $\begin{array}{l}\text { Match } \\
\text { availability (\%) }\end{array}$ & 81.7 & 88.5 & 87.5 & 0.013 \\
\hline
\end{tabular}

Values represent the medians in each group.

*Communication quality was classified as low, moderate or high, based on overall questionnaire scores.

†Significance was based on Kruskal-Wallis tests.

\#Injury burden=number of days of absence per 1000 hours of exposure $(\Sigma$ days of absence $/ \Sigma$ hours of exposure $\times 1000$ ).

§lncidence of severe injuries=number of severe injuries (resulting in $>28$ days of absence from trainings and matches) per 1000 hours of exposure ( $\Sigma$ severe injuries/ इexposure hours $\times 1000$ ).

with teams with moderate ( $\mathrm{p}=0.002$ and 0.004 , respectively) or high ( $\mathrm{p}=0.002$ and 0.007 , respectively) communication quality.

The effect size was 0.5 for injury rates and 0.6 for availability, indicating a strong effect.

\section{Communication between the doctors and physiotherapists}

Only one team had low scores for communication between doctors and physiotherapists (table 2).

Teams with high communication quality within the medical team $(n=70)$ had lower injury rates and higher attendance at training compared with teams with low-moderate scores $(n=7)$. The effect sizes was 0.25 for all variables.

\section{Communication between the medical team and the fitness coaches}

The attendance at training was significantly lower (by 4\%-5\%) for teams with low communication quality between the medical team and the fitness coaches compared with teams with high communication quality (table 3 ). The effect size was 0.37 .

Communication between the medical team and the CEO or board/president of the club was not associated with rates of team injury or player availability (tables 4 and 5 ).

Table 2 Communication quality* between team doctors and team physiotherapists

\begin{tabular}{lccl}
\hline Outcomes* & $\begin{array}{l}\text { Low-moderate } \\
(1-3), \mathrm{n}=\mathbf{7}\end{array}$ & $\begin{array}{l}\text { High (4-5), } \\
\mathrm{n}=70\end{array}$ & P values $\boldsymbol{~}$ \\
\hline Injury burden $\neq$ & 209.6 & 112.6 & 0.029 \\
Incidence of severe injuries§ & 1.6 & 1.0 & 0.028 \\
\hline Training attendance (\%) & 79.1 & 84.1 & 0.045 \\
Match availability (\%) & 83.9 & 87.7 & 0.178 \\
\hline
\end{tabular}

Values represent the medians in each group.

*Communication quality was classified as low, moderate or high, based on overall questionnaire scores.

tSignificance was based on Kruskal-Wallis tests.

FInjury burden=number of days of absence per 1000 hours of exposure $(\Sigma$ days of absence $/ \Sigma$ hours of exposure $\times 1000$ ).

§Incidence of severe injuries=number of severe injuries (resulting in $>28$ days of absence from trainings and matches) per 1000 hours of exposure ( $\Sigma$ severe injuries/ Eexposure hours $\times 1000$ ).
Table 3 Communication quality* between the medical team and the fitness coaches

\begin{tabular}{|c|c|c|c|c|}
\hline Outcomes* & $\begin{array}{l}\text { Low }(1-2 / 5) \text {, } \\
n=8\end{array}$ & $\begin{array}{l}\text { Moderate } \\
(3 / 5), n=18\end{array}$ & $\begin{array}{l}\text { High }(4-5 / 5), \\
n=51\end{array}$ & $P$ valuest \\
\hline Injury burden‡ & 184.4 & 126.9 & 106.3 & 0.064 \\
\hline $\begin{array}{l}\text { Incidence of } \\
\text { severe injuries§ }\end{array}$ & 1.2 & 1.2 & 1.0 & 0.132 \\
\hline $\begin{array}{l}\text { Training } \\
\text { attendance (\%) }\end{array}$ & 79.7 & 85.0 & 84.2 & 0.022 \\
\hline $\begin{array}{l}\text { Match } \\
\text { availability (\%) }\end{array}$ & 85.7 & 86.7 & 87.8 & 0.305 \\
\hline
\end{tabular}

Values represent the medians in each group.

Communication between the medical team and the administration.

${ }^{*}$ Communication quality was classified as low, moderate or high, based on overall questionnaire scores.

tSignificance was based on Kruskal-Wallis tests.

‡Injury burden=number of days of absence per 1000 hours of exposure $(\Sigma$ days of absence $/ \Sigma$ hours of exposure $\times 1000$ ).

§Incidence of severe injuries=number of severe injuries (resulting in $>28$ days of absence from trainings and matches) per 1000 hours of exposure ( $\Sigma$ severe injuries/ इexposure hours $\times 1000$ ).

\section{DISCUSSION}

In this study, the quality of internal communication within a team was associated with both injury rates and player availability. Teams with high internal communication quality had lower injury rates and higher player availability than teams with low communication quality.

To our knowledge, no previous studies evaluated correlations between intra-team communications and injuries or performance in football. However, Lausic et $a l^{7}$ explored the role of communication in women's doubles tennis. They reported that winning teams exchanged twice as many messages and had a more homogenous model of communication compared with losing teams. ${ }^{7}$ Several studies have shown that, in well-functioning teams, there was open communication about both strengths and weaknesses, and poor communication was a marker of dysfunctional relationships. ${ }^{13} 14$

Communication between the head coach/manager and the medical team was vital for maintaining players on the field The most important finding of the study was that the internal communication between the head coach and the medical team

Table 4 Communication quality* between the medical team and the chief executive officer of the club

\begin{tabular}{|c|c|c|c|c|}
\hline Outcomes* & $\begin{array}{l}\text { Low }(1-2 / 5) \text {, } \\
n=14\end{array}$ & $\begin{array}{l}\text { Moderate } \\
(3 / 5), n=17\end{array}$ & $\begin{array}{l}\text { High }(4-5 / 5) \text {, } \\
n=46\end{array}$ & $P$ valuest \\
\hline Injury burden‡ & 146.8 & 139.9 & 106.5 & 0.135 \\
\hline $\begin{array}{l}\text { Incidence of } \\
\text { severe injuries§ }\end{array}$ & 1.2 & 1.0 & 0.9 & 0.253 \\
\hline $\begin{array}{l}\text { Training } \\
\text { attendance (\%) }\end{array}$ & 82.9 & 82.2 & 85.3 & 0.102 \\
\hline $\begin{array}{l}\text { Match } \\
\text { availability (\%) }\end{array}$ & 85.8 & 86.9 & 88.3 & 0.235 \\
\hline
\end{tabular}

Values represent the medians in each group.

*Communication quality was classified as low, moderate or high, based on overall questionnaire scores.

tSignificance was based on Kruskal-Wallis tests.

\#Injury burden=number of days of absence per 1000 hours of exposure $(\Sigma$ days of absence $/ \Sigma$ hours of exposure $\times 1000$ ).

§Incidence of severe injuries=number of severe injuries (resulting in $>28$ days of absence from trainings and matches) per 1000 hours of exposure ( $\Sigma$ severe injuries/ इexposure hours $\times 1000$ ). 


\begin{tabular}{|c|c|c|c|c|}
\hline Outcomes ${ }^{*}$ & $\begin{array}{l}\text { Low }(1-2 / 5), \\
n=21\end{array}$ & $\begin{array}{l}\text { Moderate } \\
(3 / 5), n=16\end{array}$ & $\begin{array}{l}\text { High }(4-5 / 5) \text {, } \\
n=40\end{array}$ & $P$ valuest \\
\hline Injury burden‡ & 147.9 & 127.2 & 107.2 & 0.159 \\
\hline $\begin{array}{l}\text { Incidence of } \\
\text { severe injuries§ }\end{array}$ & 1.2 & 1.2 & 0.9 & 0.113 \\
\hline $\begin{array}{l}\text { Training } \\
\text { attendance (\%) }\end{array}$ & 83.4 & 82.7 & 85.6 & 0.141 \\
\hline $\begin{array}{l}\text { Match } \\
\text { availability (\%) }\end{array}$ & 86.8 & 86.0 & 88.9 & 0.114 \\
\hline
\end{tabular}

Values represent the medians in each group.

*Communication quality was classified as low, moderate or high, based on overall questionnaire scores.

†Significance was based on Kruskal-Wallis tests.

¥Injury burden=number of days of absence per 1000 hours of exposure $(\Sigma$ days of absence $/ \Sigma$ hours of exposure $\times 1000$ ).

§lncidence of severe injuries=number of severe injuries (resulting in $>28$ days of absence from trainings and matches) per 1000 hours of exposure ( $\Sigma$ severe injuries/ इexposure hours $\times 1000$ ).

was the most influential (based on effect size). The effect was greatest between low and either moderate or high communication quality. Indeed, we found that low or poor communication quality between the head coach and the medical team could was significantly associated with the injury rate; such teams had a $6 \%-7 \%$ lower player availability at training and matches and a $50 \%$ higher injury burden, compared with teams with moderate or high communication quality.

The injury burden and player availability at training and matches were good indicators of the consequences that injuries had on a team. Injuries are associated with performance in league and UEFA club competitions. ${ }^{11}$ Thus, in elite sports, players are commonly pressured to return to play after an injury. ${ }^{15}$ We speculate that good and clear communication between the medical team and the coach and manager throughout the rehabilitation process might provide continual management of expectations. This could narrow the probability of a premature return from injury, and therefore, minimise the risk of a subsequent re-injury. ${ }^{16}$

Modification of training load requires optimal communication Injury prevention strategies should be highly individualised at an elite level. Individualised care requires well-developed communication pathways between all staff disciplines. However, without effective lines of communication, it is nearly impossible to make modifications in training load, training monotony and training surface to fit each individual player, considering age, position and medical history.

\section{Communication between the medical team and the sports scientists is a key factor}

Loading has traditionally been the realm of Sports Science. However, medical teams have been improving their understanding of basic load management. Consequently, they are playing a greater role in preventing injury related to load management, particularly in less robust players.

Communication can occur in person or electronically. Electronically is a form of non-verbal communication where the communication is passed through sending and receiving wordless cues. It includes data transfer and access to athlete management systems and electronic player data and metrics (GPS, wellness scores, etc). This information can also assist in injury prevention.
For example, if the clinician learns early that a certain player must increase his amount of high speed running, the clinician can intervene earlier and provide more focused and intensive care, which could potentially reduce the risk of injury. As the season progresses, players will continue to play, despite small injures. Good communication, management and training restrictions can ensure that they can continue playing and performing throughout the season without exacerbating the injury.

\section{Theoretical framework}

This prospective epidemiological study revealed some significant associations. However, the study design did not allow evaluations of causative factors. Nevertheless, here we speculate three ways that communication may affect injuries and player availability.

Communication has often been highlighted as a central factor for a well-functioning team. ${ }^{14-21}$ High-quality communication between individuals in different roles is likely to promote good collaborations and facilitate the benefits derived from multiple perspectives in informed decisions, for instance, return to play decision or major decisions regarding the well-being of players. On the other hand, low-quality communication is likely to increase the risk of misunderstandings and promote one-sided decision-making.

Communication has been suggested to be an indicator of organisational (think 'team' in this case) stress. ${ }^{1422}$ For example, when an organisation has frequent miscommunications and members receive insufficient or no information or feel that their opinions are not considered, stress can burden members and players, and this has the potential to increase injury rate. ${ }^{14} 23-25$ Organisational stress, environmental demands experienced by an individual associated with an organisation, has been reported as a significant source of stress among coaches. ${ }^{26}$ One aspect of this stress could arise from cultural or language differences; in particular, language challenges could influence the dynamics of this type of stress. ${ }^{27} 28$ The constant transfer of coaches and players from different nations between different clubs leads to changes in the workplace which likely adds to cultural and communication challenges. ${ }^{29}$

The quality of communication could also be a mediating variable between coaches' leadership and players' injuries and availability. In the ECIS, we previously showed that the coach's leadership style was correlated with the incidence of severe injuries and player availability. The incidence of severe injuries on a team was significantly lower with coaches that employed a transformational or democratic leadership style than with coaches that employed more aggressive styles. ${ }^{30}$ Effective coach leadership requires communicating frequently with individuals who perform different functions and roles on the team. ${ }^{31}$ Leadership styles that promote high-quality communication were suggested to enhance team cohesion. Highly cohesive teams worked together more efficiently, and consequently, performed better than less cohesive teams. ${ }^{32} 33$ In contrast, leadership that does not promote high-quality communication might risk insufficient collaboration within the team, poor decision-making and high stress, which in the long run might cause injuries. This scenario was supported by a recent study on female football players that perceived their coach as a source of stress due to poor communication; that team showed a high risk of developing overuse injuries. On the other hand, players who perceived their teammates as a source of stress (internal conflict) showed a high risk of developing acute injuries. ${ }^{34}$ Clearly, those findings indicated that we need to improve our understanding of the interplay among 
psychosocial, physiological and biomechanical parameters to enhance the methods for preventing injuries.

\section{Methodological considerations}

This study had several strengths. The main strength was the substantial dataset, which comprised a homogeneous group of male professional footballers. In addition, the ECIS is an appropriate, reliable, useful tool for evaluating injury risk and injury patterns in elite male footballers. ${ }^{9}$

However, this study had some limitations. First, we depended on the opinions of medical staff regarding internal communication within their clubs. Their opinions were subjective and not necessarily representative of the views of other team members. Nevertheless, at this level, doctors work with their teams on a full-time basis and see the other staff members and players every day. In our opinion, this proximity and their medical training made the medical staff members the best candidates for observing and evaluating communications within the club. Note that we did not test the reliability of the health professionals' opinions. We did not ask the same person to provide their opinion a week later.

Second, evaluations were carried out at the end of each season; thus, the opinions of the medical staff could be influenced by the team's performance during the season, which represented a potential bias. Indeed, doctors at clubs with high injury rates might have viewed those injuries as a sign of poor internal communication. Third, although data on the injuries and availability of players were collected prospectively, the data on communication were only collected once per season; thus, the latter analysis had a more cross-sectional design. Cross-sectional studies do not capture dynamic changes in relationships and behaviours over the course of a season. Therefore, the relationships found in that analysis were not necessarily causative. ${ }^{35}$

We describe this novel association between communication quality and injury but it is unclear that poor communication causes poor injury rates, just that they are seen in association with each other. We did consider whether reverse causality effect might explain some of our findings. That would be the case when there is low player availability due to factors such

What are the new findings?

- Elite football clubs with good quality internal communication had fewer injuries and greater player availability compared with clubs with poor communication.

- The communication between the head coach/manager and the medical team was associated with team injury rates.

- The quality of communication within the medical team, between doctors and physiotherapists, was generally very good in these elite football teams; however, in rare cases of poor communication, player availability at training was affected negatively.

- Teams with low communication quality between the medical team and the fitness coaches had low player attendance at training.

\section{How might it impact on clinical practice in the future?}

- This study can provide club medical teams with data to support developing team programs that underpins developing communications skills. as injuries on international duty or non-playing accidents, and poor communication follows. The study design did not evaluate this. Furthermore, the study did not consider the situation where medical staff were asked for their opinion and then ignored by the coaching staff, and where medical staff were simply not asked their opinion.

Finally, this study only covered elite men's football; thus, the findings are not generalisable to other areas of football, such as amateur, youth and women's football (or, indeed, other sports).

Acknowledgements The authors wish to thank all participating clubs, including all coaches, players and medical staff. A special thanks to the head team physician, Dr Craig Roberts (AFC Bournemouth), for his most appreciated comments and his contribution to this paper. Thanks also go to biostatistician Henrik Hedevik for his assistance with the statistical analysis.

Contributors JE was responsible for the conception and design of the study and for the data collection over the study period. JE conducted the analyses in collaboration with the biostatistician (HH). All authors contributed to the interpretations of the findings. JE wrote the first draft of the paper, which was critically revised by MD, MD'H, DL and AMP. The final manuscript was approved by all authors. JE is the study guarantor.

Funding The Football Research Group was established in Linkoping, Sweden, in cooperation with Linkoping University. It was supported by grants from UEFA, the Swedish Football Association and the Swedish Research Council for Sport Science.

Competing interests None declared.

Patient consent Not required.

Provenance and peer review Not commissioned; externally peer reviewed.

Open access This is an open access article distributed in accordance with the Creative Commons Attribution Non Commercial (CC BY-NC 4.0) license, which permits others to distribute, remix, adapt, build upon this work non-commercially, and license their derivative works on different terms, provided the original work is properly cited, appropriate credit is given, any changes made indicated, and the use is non-commercial. See: http://creativecommons.org/licenses/by-nc/4.0/.

\section{REFERENCES}

1 Ekstrand J, Hägglund M, Kristenson K, et al. Fewer ligament injuries but no preventive effect on muscle injuries and severe injuries: an 11-year follow-up of the UEFA Champions League injury study. Br J Sports Med 2013;47:732-7.

2 Ekstrand J, Waldén M, Hägglund M. Hamstring injuries have increased by $4 \%$ annually in men's professional football, since 2001: a 13-year longitudinal analysis of the UEFA Elite Club injury study. Br J Sports Med 2016;50:731-7.

3 Ekstrand J. Preventing injuries in professional football: thinking bigger and working together. Br J Sports Med 2016;50:709-10.

4 Bahr R, Clarsen B, Ekstrand J. Why we should focus on the burden of injuries and illnesses, not just their incidence. Br J Sports Med 2017:bjsports-2017-098160.

5 Ekstrand J. Keeping your top players on the pitch: the key to football medicine at a professional level. Br J Sports Med 2013;47:723-4.

6 McCall A, Dupont G, Ekstrand J. Injury prevention strategies, coach compliance and player adherence of 33 of the UEFA Elite Club Injury Study teams: a survey of teams head medical officers. Br J Sports Med 2016;50:725-30.

7 Lausic D, Tennebaum G, Eccles D, et al. Intrateam communication and performance in doubles tennis. Res Q Exerc Sport 2009;80:281-90.

8 Fuller CW, Ekstrand J, Junge A, et al. Consensus statement on injury definitions and data collection procedures in studies of football (soccer) injuries. Br J Sports Med 2006; 40:193-201.

9 Hägglund M, Waldén M, Bahr R, et al. Methods for epidemiological study of injuries to professional football players: developing the UEFA model. Br J Sports Med 2005;39:340-6.

10 Orchard J. Orchard sports injury classification system (Osics). Sports Health 1993;11:39-41.

11 Hägglund $M$, Waldén $M$, Magnusson $H$, et al. Injuries affect team performance negatively in professional football: an 11-year follow-up of the UEFA Champions League injury study. Br J Sports Med 2013;47:738-42.

12 Cohen J. Statistical power analysis for the behavioral sciences. Mahwah(NJ): Lawrence Erlbaum Publishing Company, 1988.

13 Jowett S, Shanmugam V. Relational Coaching in Sport: Its Psychological underpinnings and practical Effectiveness. In: Schinke R, McGannom KR, Smith B, Routledge International Handbook of Sport Psychology: Routledge, 2006.

14 Kristiansen E, Halvari H, Roberts GC. Organizational and media stress among professional football players: testing an achievement goal theory model. Scand J Med Sci Sports 2012;22:569-79. 
15 Podlog L, Dimmock J, Miller J. A review of return to sport concerns following injury rehabilitation: practitioner strategies for enhancing recovery outcomes. Phys Ther Sport 2011;12:36-42.

16 Grindem H, Snyder-Mackler L, Moksnes H, et al. Simple decision rules can reduce reinjury risk by $84 \%$ after $A C L$ reconstruction: the Delaware-Oslo $A C L$ cohort study. $B r$ J Sports Med 2016;50:804-8.

17 McCalla T, Fitzpatrick S. Integrating sport psychology within a high-performance team: Potential stakeholders, micropolitics, and culture. J Sport Psychol Action 2016;7:33-42.

18 Reid C, Stewart E, Thorne G. Multidisciplinary Sport Science Teams in Elite Sport: Comprehensive Servicing or Conflict and Confusion? Sport Psychol 2004;18:204-17.

19 McDougall M, Nesti M, Richardson D. The challenges of sport psychology delivery in elite and professional sport: reflections from experienced sport psychologists. Sport Psychol 2015;29:265-77.

20 Eubanks M, Nesti M, Cruickshank A. Understanding high performance sport environments: Impact for the professional training and supervision of sport psychologists. Sport Exer Psychol Rev 2014;10:30-7.

21 O'Brien J, Young W, Finch CF. The delivery of injury prevention exercise programmes in professional youth soccer: Comparison to the FIFA 11. I Sci Med Sport 2017;20:26-31.

22 Arnold R, Fletcher D. A research synthesis and taxonomic classification of the organizational stressors encountered by sport performers. J Sport Exerc Psychol 2012;34:397-429.

23 Ivarsson A, Johnson U, Andersen MB, et al. Psychosocial Factors and Sport Injuries: Meta-analyses for Prediction and Prevention. Sports Med 2017;47:353-65.

24 Williams JM, Andersen MB. Psychosocial antecedents of sport injury: Review and critique of the stress and injury model'. J App/ Sport Psychol 1998;10:5-25.
25 Singh $\mathrm{H}$, Conroy DE. Systematic review of stress-related injury vulnerability in athletic and occupational contexts. Psychol Sport Exerc 2017;33:37-44.

26 Fletcher D, Arnold R. Performance leadership and management in elite sport: Current status and future directions. In: Andersen S, Houlihan B, Ronglan LT, eds. Managing Elite Sport Systems: Research and Practice. Abingdon, UK: Routledge, 2015:162-81.

27 Schinke R, Moore ZE. Culturally informed sport psychology: introduction to the special issue. J Clin Sport Psychol 2011;5:283-94.

28 Moore ZE. Working with transnational professional athletes. In: Schinke RJ, Hackfort D, eds. Psychology in professional sports and the performing arts. New York NY: Routledge, 2017:51-62.

29 Parham WD. Raising the bar: Developing an understanding of culturally, ethnically and racially diverse athletes. Andersen M, ed. Practicing sport psychology. Champaign, IL:Human Kinetics, 2005:211-9.

30 Ekstrand J, Lundqvist D, Lagerbäck L, et al. Is there a correlation between coaches' leadership styles and injuries in elite football teams? A study of 36 elite teams in 17 countries. Br J Sports Med 2017.

31 Molan C, Matthews J, Arnold R. Leadership off the pitch: the role of the manager in semi-professional football. European Sport Management Quarterly 2016;16:274-91.

32 Smith MJ, Arthur CA, Hardy J, et al. Transformational leadership and task cohesion in sport: The mediating role of intrateam communication. Psychol Sport Exerc 2013;14:249-57.

33 Carron AV, Spink KS. Team building in an exercise setting. Sport Psychol 1993;7:8-18.

34 Pensgaard AM, Ivarsson A, Nilstad A, et al. Psychosocial stress factors, including the relationship with the coach, and their influence on acute and overuse injury risk in elite female football players. BMJ Open Sport Exerc Med 2018;4:e000317.

35 Hampson R, Jowett $\mathrm{S}$. Effects of coach leadership and coach-athlete relationship on collective efficacy. Scand J Med Sci Sports 2014;24:454-60. 